\title{
Emergent patterns of social organization in captive Cercocebus torquatus: Testing the GrooFiWorld agent-based model
}

\author{
R DOLADO $^{l, *}$ and FS BELTRAN ${ }^{2}$ \\ ${ }^{I}$ Department of Behavioral Sciences Methods, ${ }^{2}$ Institute for Brain, Cognition and Behavior (IR3C), Adaptive Behavior \\ and Interaction Research Group, University of Barcelona, Barcelona, Spain \\ *Corresponding author (Fax, +34 9340213 59; Email, ruth.dolado@ub.edu)
}

\begin{abstract}
We empirically applied the GrooFiWorld agent-based model (Puga-González et al. 2009) in a group of captive redcapped mangabeys (Cercocebus torquatus). We analysed several measurements related to aggression and affiliative patterns. The group adopted a combination of despotic and egalitarian behaviours resulting from the behavioural flexibility observed in the Cercopithecinae subfamily. Our study also demonstrates that the GrooFiWorld agent-based model can be extended to other members of the Cercopithecinae subfamily generating parsimonious hypotheses related to the social organization.

[Dolado R and Beltran FS 2012 Emergent patterns of social organization in captive Cercocebus torquatus: Testing the GrooFiWorld agent-based model. J. Biosci. 37 777-784] DOI 10.1007/s12038-012-9231-5
\end{abstract}

\section{Introduction}

Social organization in primates is based on the interaction of several agonistic and affiliative behaviours, as well as other intrinsic factors such as kinship. Hierarchical relationships define this social organization and are developed through competition among individuals involving contests over access to essential resources and females (van Schaik 1989; van Hooff and van Schaik 1992). These relationships are usually maintained by aggressive and affiliative interactions that result in the formation and maintenance of dominance hierarchies (Slatter 1986).

Aggressive interaction among members of the same group produces power asymmetries that are characteristic of many primate societies (de Waal 1986). When power is distributed asymmetrically, unidirectional status indicators are usually observed that replace violent encounters. However, when power is more balanced, an exchange of agonistic encounters is generally observed (Preuschoft and van Schaik 2000). These aggression patterns have been closely studied in macaques with the aim of establishing well-defined dominance hierarchies (for example, for the species Macaca fuscata and Macaca silenus, see Singh et al. 2003 and Singh et al. 2006, respectively) and different dominance styles (Thierry 2004).
Affiliative behaviour is another important factor in the construction of social organization in the Cercopithecinae. One of the most frequent behaviours involved is allogrooming (hereinafter referred to as grooming). Many research papers and reviews have been published on the functions of grooming: it is involved in hygienic functions (Pérez and Veà 2000), reducing social tension and thus reintegrating individuals into a social group (Terry 1970; Goosen 1987), reconciliation between individuals and strengthening social bonds (Dunbar 1988). Although biological market theory postulates that grooming is involved in social reciprocation and exchange processes (Noë and Hammerstein 1995), many of the explanations regarding grooming functions based on market theory require cognitive sophistication because the individuals concerned must remember specific grooming sessions in order to assess the current situation and make the best decision. However, the co-variation hypothesis offers an integrative approach based on fewer cognitive processes, where agonistic and affiliative behaviours act simultaneously to help individuals deal with intra-group conflict (Preuschoft and van Schaik 2000). According to the co-variation hypothesis, the species of the genus Macaca are classified in 4 grades or social styles in which the level of inter-individual

Keywords. Agent-based model; Cercopithecinae; emergent patterns; social organization 
Table 1. Classification of social styles for the genus Macaca, where inter-individual tolerance ranges from 1 to 4

\begin{tabular}{llll}
\hline $\begin{array}{c}\text { Grade } 1 \text { or } \\
\text { despotic }\end{array}$ & $\begin{array}{c}\text { Grade } 2 \text { or } \\
\text { tolerant }\end{array}$ & \multicolumn{1}{c}{$\begin{array}{c}\text { Grade } 3 \text { or } \\
\text { relaxed }\end{array}$} & \multicolumn{1}{c}{$\begin{array}{c}\text { Grade } 4 \text { or } \\
\text { egalitarian }\end{array}$} \\
\hline M. mulatta & M. fascicularis & M. sylvanus & M. tonkeana \\
M. fuscata & M. nemestrina & M. silenus & M. maurus \\
M. cyclopis & & M. arctoides & M. nigra \\
& & M. radiata & M. nigrescens \\
& & M. assamensis & M. hecki \\
& & M. thibetana & M. ochreata \\
& & M. sinica & M. brunnescens
\end{tabular}

Table adapted from Thierry (2004).

tolerance can range from 1 to 4 (table 1). Grades 1 and 2 are used to classify more despotic societies, in which conflicts are usually avoided by means of submission signals and where highly intensive agonistic encounters are rare. Grades 3 and 4 are used to classify more tolerant societies, where subordinates are reluctant to submit and agonistic encounters occur more frequently than in despotic societies, although the intensity is much lower (Thierry 2006).

Puga-González et al. (2009) developed an agent-based model based on the co-variation hypothesis called GrooFiWorld. This computer model is an extension of a grouping and competition model called DomWorld (Hemelrijk 1998, 2000), which shows the patterns of aggression, dominance and spatial distribution in macaque societies. GrooFiWorld includes grooming encounters in order to integrate agonistic and affiliative behaviours and produce the emergence of patterns of social affiliation that are similar to the patterns observed in macaque societies. GrooFiWorld consists of a continuous micro-world containing different agents that are free to move in any direction. Agents are defined with different adjustable parameters: (a) perspace, nearview and maxview define the close, medium and maximum distance of perception of others agents, respectively; (b) vision angle defines the angle of field of view assigned to agents; (c) search angle defines the turning angle to find others agents; and (d) stepdom defines a scaling factor for aggression intensity. Whenever an agent does not see any other agent in its personal space (or perspace), grouping rules come into effect. However, if one agent enters the personal space of another, social interaction may or may not take place. When two agents meet, one decides whether or not it will engage in dominance or affiliative interaction. Dominance interactions are based on two agonistic strategies and modelled according to the different dominance rules used in DomWorld (Hemelrijk 1998). The agonistic strategies in DomWorld consist of an 'ambiguity-reducing strategy', in which agents attack others whose rank is similar to their own, and a 'risk-sensitive strategy', in which agents attack others whose rank is significantly different from their own. Therefore, if an agent expects to win, dominance interaction takes place, i.e. the agent's dominance value is compared to a random value and if its dominance value is greater than the random value, it wins the interaction. If its dominance value is lower, it loses. An agent only considers grooming its partner if it expects to be defeated. Grooming behaviour is modelled according to the level of anxiety: when the anxiety value is higher than the random value, the agent grooms its counterpart; otherwise, the agent displays non-aggressive proximity without interacting socially with the other agent (table 2).

Puga-González et al. (2009) tested The GrooFiWorld agent-based model by running simulations. The authors defined two conditions that were classified as high and low aggression intensity, in accordance with two dominance styles observed in macaque societies (despotic and egalitarian societies) (Thierry 2004) and also defined all different adjustable parameters described above which were fitted with the characteristics observed in the macaque societies. The results obtained by running simulations under both conditions showed that at high aggression intensity: (a) the gradient of the hierarchy was significantly steeper than at

Table 2. Default parameter values in GrooFiWorld

\begin{tabular}{lll}
\hline & Females & Males \\
\hline General parameters & & \\
Sex ratio (at high aggression intensity) & 10 & 2 \\
Sex ratio (at low aggression intensity) & 8 & 4 \\
InitRadius (zone at start of simulation) & $1.7 \mathrm{n}^{1}$ & $1.7 \mathrm{n}^{1}$ \\
Grouping parameters & & \\
Perspace & 8 & 8 \\
Nearview & 24 & 24 \\
Maxview & 50 & 50 \\
Search angle & $90^{\circ}$ & $90^{\circ}$ \\
Vision angle & $120^{\circ}$ & $120^{\circ}$ \\
Dominance parameters & & \\
Initial Dominance value & 16 & 32 \\
Risk Sensitive (chance to win a dominance & 2 & 2 \\
interaction) & & \\
Stepdom (high aggression intensity) & 0.8 & 1 \\
Stepdom (low aggression intensity) & 0.08 & 0.1 \\
Fleeing distance (after loosing fight) & 2 & 2 \\
Grooming parameters & & \\
Initial anxiety value & 0.5 & 0.5 \\
Increase in anxiety after every activation & 0.1 & 0.1 \\
Decrease in anxiety in groomee & 0.15 & 0.15 \\
Decrease in anxiety in groomer & 0.1 & 0.1 \\
Increase in anxiety after fighting & 0.1 & 0.1 \\
\hline
\end{tabular}

Table adapted from Puga-González et al. (2009).

${ }^{1} \mathrm{n}=$ number of agents. 
low intensity; (b) aggression was more unidirectional; (c) less time was spent fighting; (d) proximity levels among individuals were high; (e) the dominant individuals occupied distinctly central positions; and (f) grooming appeared to be reciprocated (although this was also true at low intensity). These simulation results were consistent with several findings obtained on macaques (Yamada 1966; de Waal and Luttrell 1989; Thierry 2004 and Schino and Aureli 2008). However, Puga-González et al. (2009, p 3 ) concluded that 'Part of these predicted patterns appear also to be found in empirical data described by scientists in other contexts. Other patterns still need to be tested empirically'. The aim of our study was therefore to compare the data obtained from empirical observation of a group of captive mangabeys (Cercocebus torquatus) with the results obtained by Puga-González et al. (2009).

Although GrooFiWorld focuses on the patterns of social aggression and affiliation in macaque societies, we believe that it can be extended to other genera of the Cercopithecinae subfamily. Some close taxonomic groups such as mangabeys (Cercocebus) demonstrate the great variety of social behaviour typical of macaques (Gust and Gordon 1993). In addition, the small morphological constitution of Cercocebus allows these animals to adapt well to captivity, as they are able to establish stable groups. Captive studies also provide an opportunity to control primates' social and physical environments. They also offer the advantage of providing better observation conditions, and in many cases, the individual histories of the primates are well known to the observers. Based on Cercocebus's characteristics (i.e. social behaviour similar to that of macaques and the formation of stable groups in captivity), we decided that this genus was a suitable candidate to compare the empirical results with those obtained from GrooFiWorld simulations using the GrooFiWorld model. Thus, our aim was to obtain data from a captive group of $C$. torquatus and compare them to the results obtained by Puga-González et al. (2009) from their GrooFiWorld simulations.

\section{Materials and methods}

\subsection{Subjects}

The study of the group of red-capped mangabeys (C. torquatus) was carried out at Barcelona Zoo. The group studied consisted of 7 individuals: 1 adult male, 2 adult females, 2 subadult males and 2 infant males. Pascal was an adult male born in 1999 that arrived at Barcelona Zoo in February 2006. Buna and Yambo were sisters born in Barcelona Zoo in 2000 and 2002, respectively. Buna spent 5 years at Hanover Zoo, whereas Yambo had never left Barcelona Zoo. Yambo gave birth to Mabé in April 2007 and Ndeko in September 2008, and Buna gave birth to Mwana in May 2007 and Ngungui in April 2009. At the time of this study, both sub-adults and one infant (Ndeko) were completely independent, but the youngest infant (Ngungui) usually stayed in close proximity to its mother. All the animals were well habituated to human observers and individual recognition was quite easy.

\subsection{Study site}

The group of $C$. torquatus at Barcelona Zoo lived in a facility with an area of approximately $23.25 \mathrm{~m}^{2}$ with walls over $4.86 \mathrm{~m}$ high. Their environment was enriched with items such as ropes, nets and pieces of wood. The facility was located outdoors but had a covered area that protected the group from inclement weather. It also had a glass front through which the animals could be observed. In addition, the group had access all day to the dorms (an area of $4.5 \mathrm{~m}^{2}$ with walls over $2 \mathrm{~m}$ high). Food consisted of a varied diet of fruits and vegetables enriched with nuts and fodder that was provided at least twice a day.

\subsection{Materials}

The group was filmed using a Sony DCR-SR72 video camera placed outside the facility in front of the glass. To ensure good image quality and avoid reflection produced by the sun on the glass, we set up large sheets of black plastic around the camera to block the sun. This equipment was set up each morning when the animals were not present and taken down after each filming session.

\subsection{Procedure}

First, we carried out ad libitum and focal samplings in order to establish a social ethogram (agonistic and affiliative behaviours) based on the one presented previously (Dolado and Beltran 2011). Then we filmed $40 \mathrm{~h}$ (2400 $\mathrm{min})$ of footage on the video camera over the course of 96 observation sessions. Data were collected early each morning (8 a.m. to 10 a.m.) from Monday to Friday when no members of the public were present. The filmed observations were used to analyse the aggressive behaviours (agonistic encounters) and the spatial distribution of the individuals. We then used OBSERVER XT 6.0.16 (2005) to observe the behaviours filmed. In addition, we also carried out focal samplings of the animals in order to obtain data on affiliative behaviour (grooming encounters). We recorded $40 \mathrm{~h}$ (2400 $\mathrm{min}$ ) over the course of 40 observation sessions. These data were collected manually between 10 a.m. and 1 p.m. by an observer on the same days filming took place. Frequency, time and the individuals involved in grooming interactions were recorded during these observation sessions.

In order to determine the individuals' spatial distribution, we divided the facility into different subareas. Each subarea 
was defined by a point with three coordinates ( $\mathrm{x}, \mathrm{y}$ and $\mathrm{z}$ ) located in the center of each subarea. OBSERVER XT 6.0.16 (2005) was used to record the positions of the 7 individuals every $30 \mathrm{~s}$ during the 96 filmed observation sessions. These positions were then used to calculate the proximity and centrality of the individuals at each time unit.

\subsection{Measurements}

We compared the data obtained from observation of the captive group of $C$. torquatus and the results obtained by Puga-González et al. (2009) using the GrooFiWorld model in terms of several data parameters used in the GrooFiWorld simulations. The dominance hierarchy was established based on the dyadic agonistic interactions between all the members of the group. The hierarchy index was calculated in accordance with the modifications proposed by Singh et al. (2003) of the Landau index (1951) and the Appleby index (1983). After generating a win/loss matrix, we calculated the index as follows:

$$
\mathrm{h}=\left[\frac{12_{\mathrm{a}=1}^{\mathrm{n}}}{(\mathrm{n} 3-\mathrm{n})}\right] \sum\left[\frac{\mathrm{d}_{\mathrm{a}}-(\mathrm{n}-1)}{2}\right]^{2}
$$

where $d_{a}=\sum_{a=1}^{n} P_{a}$

$\mathrm{P}_{\mathrm{a}}$ refers to the proportion of encounters won by one animal against another in a dyadic encounter; $d_{a}$ is produced by adding together the $\mathrm{P}_{\mathrm{a}}$ of every subject, and $\mathrm{n}$ is the number of subjects. The next step involved calculating the values of $d_{a a}$ to avoid methodological problems and standardizing the scores to construct an interval scale for subject rank. This procedure involved calculating $\mathrm{p}$ (proportions, or $\mathrm{d}_{\mathrm{aa}} / \mathrm{n}$ ) and $\mathrm{z}$ (standard scores). In order to construct a standardized interval scale, we used the lowest $\mathrm{z}$ score (in this case, -1.48$)$ as arbitrary zero. Then we added this amount (the absolute value of 1.48) to the rest of the $\mathrm{z}$ values to obtain the final intervals of scale. These scores were then used to establish the subject's rank. We established the following dominance ranks: Pascal (5), Yambo (4), Mabé (3), Buna (2), Mwana (1). This result indicates a linear organization based on a matrilineal hierarchy in which an infant acquires its mother's rank. The scale scores obtained from the hierarchy index proposed by Singh et al. (2003) were equivalent to the Dom values proposed by Hemelrijk (1998) (table 3). Therefore, the gradient of the hierarchy among all the individuals was measured using the coefficient of variation of the scale scores (standard deviation divided by the mean) (Sokal and Rohlf 1981).

The rate of fighting (or grooming) was calculated as the frequency of aggression (or grooming) divided by the total observation time. The percentage of physical aggression (or non-physical aggression) was calculated by dividing the frequency of physical aggression (or non-physical aggression) by the frequency of aggression. The percentage of time spent grooming was calculated by dividing the time spent grooming by the total observation time. The percentage of time in which females groomed males was obtained by dividing the frequency of female grooming of males by the overall frequency of grooming, while the percentage of aggression (or affiliative) interactions that involved fighting (or grooming) was obtained by dividing the frequency of fighting (or grooming) by the overall frequency of aggression and grooming, in accordance with the parameters established in the simulation results.

We also measured the diversity of aggression (or grooming) involving neighbours by dividing the number of dyadic agonistic (or grooming) interactions observed by the total number of possible dyadic agonistic (or grooming) interactions. The diversity of partners with whom an individual performed grooming was measured using the Berger-Parker dominance index (Southwood 1978) by dividing the frequency with which an individual groomed its favourite partner by the individual's total grooming frequency.

The individuals' proximity to one another was calculated in accordance with Mardia (1972), i.e. for each individual i, $a$ unit vector towards every other individual $\mathrm{j}$ was calculated every $30 \mathrm{~s}, \mathrm{w}_{\mathrm{IJ}}=\left(\mathrm{t}_{\mathrm{ij}}, \mathrm{u}_{\mathrm{ij}} \mathrm{v}_{\mathrm{ij}}\right.$, ), with coordinates $\mathrm{t}_{\mathrm{ij}}=\left(\mathrm{x}_{\mathrm{j}}-\mathrm{x}_{\mathrm{i}}\right) /$ $\mathrm{d}_{\mathrm{ij}}, \mathrm{u}_{\mathrm{ij}}=\left(\mathrm{y}_{\mathrm{j}}-\mathrm{y}_{\mathrm{i}}\right) / \mathrm{d}_{\mathrm{ij}}$ and $\mathrm{v}_{\mathrm{ij}}=\left(\mathrm{z}_{\mathrm{j}}-\mathrm{z}_{\mathrm{i}}\right) / \mathrm{d}_{\mathrm{ij}}$, where $\left(\mathrm{x}_{\mathrm{i}}, \mathrm{y}_{\mathrm{i}}, \mathrm{z}_{\mathrm{i}}\right)$ and $\left(\mathrm{x}_{\mathrm{j}}, \mathrm{y}_{\mathrm{j}}, \mathrm{z}_{\mathrm{j}}\right)$ were the coordinates of individual $\mathrm{i}$ and individual j every $30 \mathrm{~s}$, respectively, and $\mathrm{d}_{\mathrm{ij}}$ was the distance between them. The proximity of the two individuals to one another was then the sum of their respective distances $\left(\mathrm{d}_{\mathrm{ij}}\right)$ divided by the time units. The centrality of individual i was then the module of the sum of its unit vectors towards all the other subjects. Individuals with smaller modules were more central than other individuals. The method used to test the spatial centrality of the individuals was the one used by Hemelrijk (1998) and the degree of centrality was calculated using the Kendall rank correlation between the individual's dominance rank and spatial distribution (centrality vectors of each individual every $30 \mathrm{~s}$ ).

Correlations between rank, aggression and grooming were calculated using Kendall rank correlations. Note that correlation between rank and aggression received and between rank and number of fights lost was exactly the same value, because in this empirical study we understood that receiving aggression was the same as losing an encounter, and we therefore used the same values to calculate each parameter.

The reciprocity/interchange between aggression, grooming and proximity among individuals was measured using the Tau- $\mathrm{K}_{\mathrm{r}}$ correlation (Hemelrijk 1990), which is commonly used in studies of animal behaviour (Lu et al. 2008). The Mantel test permutes the identities of the individuals in one matrix many times and calculates the matrix correlation 
Table 3. Procedure for calculating hierarchy ranks in the group of C. torquatus torquatus at Barcelona Zoo (Singh et al. 2003)

\begin{tabular}{lccccccc}
\hline & Pascal & Yambo & Mabé & Ndeko & Buna & Mwana & Ngungui \\
\hline $\mathrm{d}_{\mathrm{a}}$ & 5.750 & 4.593 & 4.310 & 2.337 & 2.183 & 1.826 \\
$\mathrm{~d}_{\mathrm{aa}}$ & 6.250 & 5.093 & 4.810 & 2.837 & 2.683 & 2.326 & 0.000 \\
$\mathrm{p}$ & 0.893 & 0.728 & 0.687 & 0.405 & 0.383 & 0.332 & 0.071 \\
$\mathrm{z}$ & 1.23 & 0.61 & 0.47 & -0.25 & -0.31 & -0.44 & -1.48 \\
Scale Score & 2.71 & 2.09 & 1.95 & 1.23 & 1.17 & $\mathbf{3}$ & $\mathbf{3}$ \\
Rank & $\mathbf{7}$ & $\mathbf{6}$ & $\mathbf{5}$ & $\mathbf{4}$ & $\mathbf{2}$ & $\mathbf{1}$ \\
\hline
\end{tabular}

coefficient for each permutation. The true value of the correlation coefficient is compared with the distribution of these random correlation coefficients to investigate its statistical significance. In accordance with Hemelrijk (1990), we used a nonparametric variant of the Mantel test $\left(\right.$ Tau- $\mathrm{K}_{\mathrm{r}}$ correlation), which considers the ranks of elements in the similarity matrix. The level of significance was calculated using 2000 permutations, as described by Hemelrijk (1990). Data for the unidirectionality of aggression and the reciprocity of grooming were obtained by correlating an actor matrix of aggression and grooming, respectively, and its transpose. Similarly, the parameters grooming up the hierarchy and grooming partners of similar rank were calculated using Tau- $\mathrm{K}_{\mathrm{r}}$ correlations. To calculate these correlations, the grooming matrix was used as the actor matrix and the partner-rank matrix was then used for grooming up the hierarchy (with the scale scores of grooming partners placed in the rows), and the similar-rank matrix was used for grooming partners of similar rank (filled with zeros except for the two closest partners, which were shown as ones), as described by Puga-González et al. (2009).

Seven of the measurements described above (rate of fighting (or grooming), percentage of non-physical and physical aggression, diversity of aggression (or grooming) neighbours, percentage of time spent in grooming, and percentage with which females groom males) are not included in the results from the simulations obtained by PugaGonzález et al. (2009). However, given the fact that all of them are commonly used in field studies of Cercopiethecinae (see, for example, Preuschoft and van Schaik 2000 and de Waal and Luttrell 1989), we decided to introduce them.

\section{Results}

The main results obtained from the comparison of the data obtained from observation of the captive group of C. torquatus and the results of simulations obtained by PugaGonzález et al. (2009) using the GrooFiWorld model are shown in table 4 . The table also includes seven measures obtained from our empirical data. When we compared the results obtained from the $C$. torquatus group with the GrooFiWorld simulation results (see Introduction), we found that (a) the gradient of the hierarchy was steep and similar to the high aggression intensity level in the simulations (gradient of the hierarchy: 0.6); (b) aggression was unidirectional (unidirectionality of aggression: -0.412); (c) the amount of time spent fighting was high (percentage of time spent fighting: $72.59 \%$ ); (d) the mean proximity between individuals was high (mean distance between group members: $0.856 \mathrm{~m}$ ); (e) the dominant individual was located peripherally (centrality of dominants: 0.234 ); and (f) grooming was significantly reciprocal (reciprocity of grooming: 0.402). In summary, results (a) and (b) agreed with the results of the simulations carried out using GrooFiWorld at high aggression intensity and (c), (d), (e) and (f) agreed with the results of the simulations carried out using GrooFiWorld at low aggression intensity.

Moreover, we categorized the 15 measurements obtained through observation as either high or low aggression intensity so that we could compare them with the simulation results. Six measurements were classified as high and 8 measurements were classified as low (table 4). As a result, the observed ratio between high and low aggression intensities, i.e. 6 to 8 , allowed us to categorize the group as an intermediate one falling between despotic and egalitarian that was probably closer to the relaxed societies described in Grade 3 (Thierry 2004). The measurement called 'Percentage of aggression interactions that involve fighting' obtained from the group of C. torquatus showed a sharp increase when compared with the results obtained by PugaGonzález et al. (2009) using GrooFiWorld.

\section{Discussion}

The results obtained by Puga-González et al. (2009) from simulations carried out using the GrooFiWorld agent-based model were empirically used to compare with behavioural patterns observed in a group of captive mangabeys (C. torquatus). The results obtained from the group of $C$. torquatus showed that the gradient of the hierarchy was steep and the unidirectionality of aggression was high. The results for both these parameters confirmed that the aggression patterns shown by this captive C. torquatus group were similar to those observed in despotic societies of macaques. 
Table 4. Data obtained from observation of captive mangabeys (C. torquatus) at Barcelona Zoo compared to data from simulations obtained using the GrooFiWorld agent-based model

\begin{tabular}{|c|c|c|c|c|}
\hline & \multirow[b]{2}{*}{$\begin{array}{l}\text { Data obtained from } \\
\text { C. torquatus }\end{array}$} & \multicolumn{2}{|c|}{$\begin{array}{l}\text { Summary of data obtained } \\
\text { using GrooFiWorld model }\end{array}$} & \multirow{2}{*}{$\begin{array}{l}\text { Correspondence between } \\
\text { C. torquatus results and } \\
\text { simulation conditions of } \\
\text { GrooFiWorld }\end{array}$} \\
\hline & & $\begin{array}{l}\text { High intensity } \\
\text { of aggression }\end{array}$ & $\begin{array}{l}\text { Low intensity } \\
\text { of aggression }\end{array}$ & \\
\hline \multicolumn{5}{|l|}{ Aggression patterns } \\
\hline Gradient of hierarchy & 0.60 & 0.86 & 0.11 & High intensity of aggression \\
\hline Unidirectionality of aggression $^{2}$ & -0.412 & -0.45 & 0.18 & High intensity of aggression \\
\hline Rate of fighting & 27.1 encounters / hour & NA & NA & NA \\
\hline $\begin{array}{l}\text { Percentage of aggression interactions } \\
\text { that involve fighting }\end{array}$ & $72.59 \%$ & $15 \%-16 \%$ & $16 \%-18 \%$ & Undefined \\
\hline $\begin{array}{l}\text { Correlation between rank and } \\
\text { aggression given }^{1}\end{array}$ & 0.571 & 0.84 & 0.61 & Low intensity of aggression \\
\hline $\begin{array}{l}\text { Correlation between rank and } \\
\text { aggression received }^{1}\end{array}$ & -0.402 & -0.86 & -0.52 & Low intensity of aggression \\
\hline $\begin{array}{l}\text { Correlation between rank and } \\
\text { number of fights lost }{ }^{1}\end{array}$ & -0.402 & -0.86 & -0.51 & Low intensity of aggression \\
\hline $\begin{array}{l}\text { Percentage of non-physical and } \\
\text { physical aggression }\end{array}$ & $57.06 \%$ and $42.94 \%$ & NA & NA & NA \\
\hline $\begin{array}{l}\text { Diversity of aggression with } \\
\text { neighbors }\end{array}$ & $100 \%$ & NA & NA & NA \\
\hline $\begin{array}{l}\text { Mean distance between group } \\
\text { members }\end{array}$ & $0.856 \mathrm{~m}$ & 17 & 10 & Low intensity of aggression \\
\hline Centrality of dominants & 0.234 & -0.56 & 0.06 & Low intensity of aggression \\
\hline Affiliative patterns & $18.22 \%$ & NA & NA & NA \\
\hline \multicolumn{5}{|l|}{ Percentage of time spent grooming } \\
\hline Rate of grooming & 10.22 encounters / hour & NA & NA & NA \\
\hline $\begin{array}{l}\text { Percentage of affiliative interactions } \\
\text { that involve grooming }\end{array}$ & $27.41 \%$ & $13 \%-23 \%$ & $28 \%-30 \%$ & Low intensity of aggression \\
\hline $\begin{array}{l}\text { Berger-Parker dominance index } \\
\text { for grooming partners }\end{array}$ & 0.325 & 0.24 & 0.20 & High intensity of aggression \\
\hline $\begin{array}{l}\text { Correlation between rank and } \\
\text { grooming given }{ }^{1}\end{array}$ & 0.485 & 0.02 & -0.14 & High intensity of aggression \\
\hline $\begin{array}{l}\text { Correlation between grooming } \\
\text { and proximity of partner }\end{array}$ & $-0.311^{*}$ & -0.55 & -0.42 & Low intensity of aggression \\
\hline Grooming reciprocation $^{2}$ & $0.402 *$ & 0.31 & 0.45 & Low intensity of aggression \\
\hline Grooming up the hierarchy ${ }^{2}$ & 0.430 & 0.44 & 0.05 & High intensity of aggression \\
\hline Grooming partners of similar rank ${ }^{2}$ & $0.180^{* *}$ & 0.25 & 0.04 & High intensity of aggression \\
\hline Diversity of grooming neighbors & $80.95 \%$ & NA & NA & NA \\
\hline $\begin{array}{l}\text { Percentage with which females } \\
\text { groom males }\end{array}$ & $55.99 \%$ & NA & NA & NA \\
\hline
\end{tabular}

In the last column, the $C$. torquatus data are classified as high intensity of aggression or low intensity of aggression, in accordance with the values obtained from Puga-González et al. (2009).

${ }^{1}$ Kendall Correlations, ${ }^{2}$ Tau $\mathrm{K}_{\mathrm{r}}$ Correlations, ${ }^{3}$ Puga-González et al. (2009), NA=not available, ${ }^{*} p<0.05$, **not significant $(p>0.05)$.

These results are entirely consistent with the matrilineal kinship-linked dominance hierarchy shown by groups of sooty mangabeys (C. torquatus atys) with offspring up to the age of three (Gust and Gordon 1991, 1994). If there were no young offspring under the age of three, the aggression patterns displayed by this group would probably have been more relaxed. These results show the importance of phenotypic flexibility in some Cercopithecinae species in shaping social structure (Sinha 2005), where a simple demography peculiarity (the presence in the group of offspring under the age of three) can modify the anticipated results of a group classified close to patterns of an egalitarian societies of macaques (Gust and Gordon 1993). These results also agree with the relatively dynamic dominance patterns showed by C. torquatus atys (Gust and Gordon 1991, 1994), where an alternation between strict matrilineal kinship-linked 
dominance hierarchy and more relaxed hierarchy patterns can be observed.

The high rate of aggression (27.1 encounters/hour) and the high percentage of time spent fighting (72.59\%) shown by this $C$. torquatus group correspond to aggression patterns similar to those expected of more relaxed societies macaques (such as Macaca arctoides; de Waal and Luttrell 1989). The results also show values close to low aggression intensity: (a) the proximity between individuals was high; (b) the dominant individual occupied peripheral positions; and (c) grooming behaviour was significantly reciprocal. However, care should be taken when analysing these results, as they may be affected by the fact that the group was in captivity. Enclosure features strongly influence the use of space in captive Cercopithecinae (Mallapur et al. 2005) and may distort the physical distances between group members, in addition to amplifying affiliative patterns (Neveu and Deputte 1996; Mallapur et al. 2005). Therefore, although studying individuals in captivity makes it possible to collect thorough measurements of aggression and affiliative behaviour and the animals' spatial location, the results should be interpreted with caution because the behaviour observed may reflect different adaptation responses to the animals' housing conditions.

When compared with the results of the simulations carried out using GrooFiWorld obtained by Puga-González et al. (2009), the values of the parameters obtained from the observations of $C$. torquatus sometimes coincided with the high aggression intensity level and sometimes with the low intensity level so, in the same group, behaviours clearly similar to those adopted by despotic societies were sometimes observed and behaviours clearly similar to those adopted by egalitarian societies were sometimes observed. This characteristic, in which a group can demonstrate different kinds of social behaviour, has been documented in some macaque species. For example, under certain ecological conditions, the usual multimale social organization observed in troops of Macaca radiata can evolve into unimale social organization, a social behaviour similar to despotic societies (Sinha et al. 2005). Therefore, although the empirical data do not completely fit the set of values predicted under high and low aggression intensity level, the model allowed us to identify specific forms of adaptation adopted by the group.

The simulation results obtained by Hemelrijk (2002) suggested that aggression intensity was a parameter that determined the kind of social style adopted by macaque societies, given that when the level of aggression was increased in her simulations, an egalitarian society became a despotic one. However, the results obtained from the captive group of $C$. torquatus observed in this study suggest that other parameters, such as affiliative patterns, should be taken into account, as shown in the GrooFiWorld simulations, in order to classify Cercopithecinae groups. Moreover, many studies have also defined kinship as a factor that can account for certain individual differences in aggressive and affiliative patterns observed among members of the same group (Chapais 2004; Call et al. 1996). It may therefore be of interest to include this factor in future versions of GrooFiWorld and to test it using empirical data.

In conclusion, the aggression and affiliative patterns demonstrated by the captive group of $C$. torquatus made it possible to extend these results to include Cercopithecinae groups. The GrooFiWorld agent-based model, which integrates aggressive and affiliative behaviours, can be used as a starting point to study the flexibility observed in behaviour patterns in several Cercopithecinae species that are similar to macaques. Thus, the GrooFiWorld agent-based model is a useful tool for generating new parsimonious hypotheses about social adaptations that produce phenotypic flexibility observed in species of the Cercopithecinae subfamily.

\section{Acknowledgements}

This project was partially funded by a grant from the Directorate General for Research of the Government of Catalonia (2009SGR-1492). We would like to thank Maria Teresa Abelló, the primate curator at Barcelona Zoo, and the other primate keepers at the zoo.

\section{References}

Appleby MC 1983 Competition in red deer stag. Social group: rank, age and relatedness of opponents. Anim. Behav. 31 913-918

Call J, Judge PG and de Waal FBM 1996 Influence of kinship and spatial density on reconciliation and grooming in rhesus monkeys. Am. J. Primatol. 39 35-46

Chapais B 2004 How kinship generates dominance structures: a comparative perspective; in Macaque societies: a model for the study of social organizations (eds) B Thierry, M Singh and W Kaumanns (Cambridge UK: Cambridge University Press) pp 186-204

Dolado R and Beltran FS 2011 Dominance hierarchy and spatial distribution in captive red-capped mangabeys (Cercocebus torquatus torquatus): testing Hemelrijk's agent-based model. Interact. Stud. 12 476-488

Dunbar RIM 1988 Primate social systems (London: Chapman and Hall)

Goosen C 1987 Social grooming in primate; in Comparative primate biology (eds) G Mitchell and J Erwin (New York, NY: Alan R. Liss) vol 2 pp 107-131

Gust AD and Gordon TP 1991 Female rank instability in newly formed groups of familiar sooty mangabeys (Cercocebus torquatus atys). Primates 32 465-471

Gust D and Gordon T 1993 Conflict resolution in sooty mangabeys. Anim. Behav. 46 685-694

Gust AD and Gordon TP 1994 The absence of a matrilineally based dominance system in sooty mangabeys, Cercocebus torquatus atys. Anim. Behav. 47 589-594 
Hemelrijk CK 1990 Models of, test for, reciprocity, unidirectionality and other social interaction patterns at a group level. Anim. Behav. 39 1013-1029

Hemelrijk CK 1998 Risk sensitive and ambiguity reducing dominance interactions in a virtual laboratory; in From animals to animals (eds) VR Pfeifer, B Blunberg, JA Meyer and SW Wilson (Cambridge, MA: MIT Press) pp 255-262

Hemelrijk CK 2000 Towards the integration of social dominance and spatial structure. Anim. Behav. 59 1035-1048

Hemelrijk CK 2002 Self-organization and natural selection in the evolution of complex despotic societies. Biol. Bull. 202 283-288

van Hooff JARAM and van Schaik CP 1992 Cooperation in competition: the ecology of primate bonds; in Coalitions and alliances in humans and other animals (eds) HA Harcourt and FBM de Waal (California: Oxford University Press) pp 357-389

Landau HG 1951 On dominance relations and the structure of animal societies: I. Effect of inherent characteristics. Bull. Math. Biophys. 13 1-19

Lu A, Koenig A and Borries C 2008 Formal submission, tolerance and socioecological models: a test with female Hanuman langurs. Anim. Behav. 76 415-428

Mallapur A, Waran N and Sinha A 2005 Use of enclosure space by captive long-tailed macaques (Macaca silenus) housed in Indian zoos. J. Appl. Anim. Welf. Sci. 8 175-185

Mardia MK 1972 Statistics of directional data (London: Academic Press)

Neveu H and Deputte BLK 1996 Influence of availability of perches on the behavioral well-being of captive, group-living mangabeys. Am. J. Primatol. 38 175-185

Noë R and Hammerstein P 1995 Biological markets. Trends Ecol. Evol. 10 336-340

Pérez A and Veà JJ 2000 Functional implications of allogrooming in Cercocebus torquatus. Int. J. Primatol. 21 255-267

Preuschoft S and van Schaik CP 2000 Dominance and communication conflict management in various settings; in Natural conflict resolution (eds) F Aureli and FBM de Waal (Berkeley: University of California Press) pp 77-105

Puga-González I, Hildenbrandt H and Hemelrijk CK 2009 Emergent patterns of social affiliation in primates, a model. PLoS Comput. Biol. 5 e1000630

van Schaik CP 1989 The ecology of social relationships amongst primate females; in Comparative socioecology: the behavioural ecology of humans and other mammals (eds) V Standen and RA Foley (Oxford: Blackwell Scientific) pp 195-218
Schino G and Aureli F 2008 Trade-offs in primate grooming reciprocation: testing behavioural flexibility and correlated evolution. Biol. J. Linn. Soc. 95 439-446

Singh M, Singh M, Sharma AK and Krishna BA 2003 Methodological considerations in measurement of dominance in primates. Curr. Sci. 8 709-713

Singh M, Krishna BA and Singh M 2006 Dominance hierarchy and social grooming in female lion-tailed macaques (Macaca silenus) in the Western Ghats, India. J. Biosci. 31 369-377

Sinha A 2005 Not in their genes: Phenotypic flexibility, behavioral traditions and cultural evolution in wild bonnet macaques. $J$. Biosci. 30 51-64

Sinha A, Mukhopadhyay, Datta-Roy A and Ram S 2005 Ecology proposes, behaviour disposes: Ecological variability in social organization and male behavioural strategies among wild bonnet macaques. Curr. Sci. 89 1166-1179

Slatter PJB 1986 Individual differences and dominance hierarchies. Anim. Behav. 34 1264-1265

Sokal RR and Rohlf FJ 1981 Biometry: the principles and practice of statistics in biological research (San Francisco: WH Freeman)

Southwood TRE 1978 Ecological methods with particular reference to the study of insect populations (London and New York: Chapman and Hall)

Terry RL 1970 Primate grooming as a tension reduction mechanism. J. Psychol. 76 129-136

Thierry B 2004 Social epigenesist; in Macaque societies: a model for the study of social organizations (eds) B Thierry, M Singh and W Kaumanns (Cambridge UK: Cambridge University Press) pp 267-290

Thierry B 2006 The macaques: a double-layered social organization; in Primates in perspective (eds) C Campell, A Fuentes, KC MacKinnon, M Panger and S Beader (New York and Oxford: Oxford University Press) pp 224-239

de Waal FBM 1986 The integration of dominance and social bonding in primates. Q. Rev. Biol. $61459-479$

de Waal FBM and Luttrell LM 1989 Towards a comparative socioecology of the genus Macaca: different dominance styles in rhesus and stumptail monkeys. Am. J. Primatol. 19 83-109

Yamada M 1966 Five natural troops of Japanese monkeys of Shodoshima Island (I): distribution and social organization. Primates 7 315-362

Corresponding editor: RENEE BoRGES 